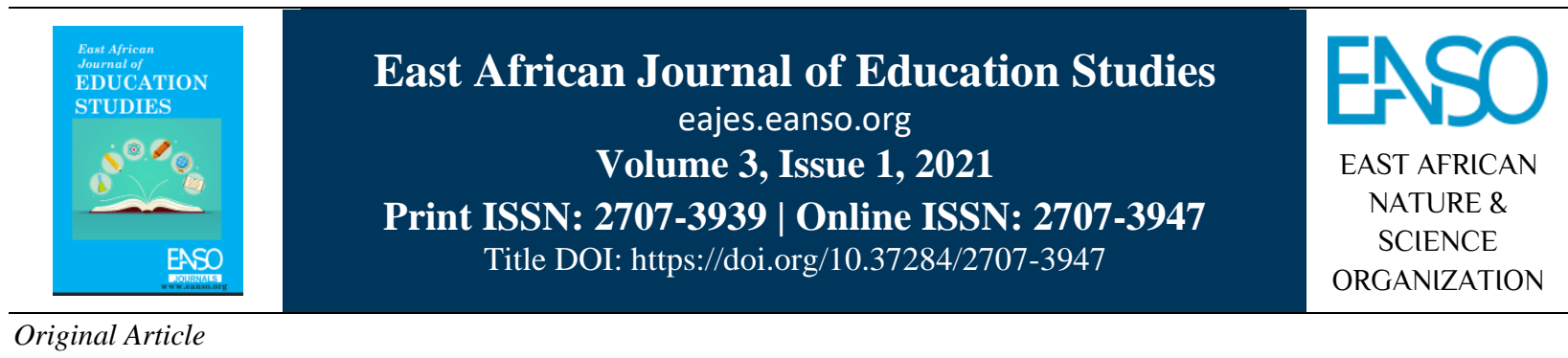

\title{
Influence of Sibling Relationships on Development of Maladjusted Behaviour among Pupils in Public Primary Schools in Yatta Sub-County, Machakos County, Kenya
}

\author{
Betty Kavwei ${ }^{* 1} \&$ Dr. Nancy Cheseto ${ }^{1}$ \\ $1^{*}$ Mount Kenya University, P. O. Box $342-01000$, Thika, Kenya. \\ *ORCID: https://orcid.org/0000-0003-0811-5673; Correspondence Email: ebetty33@ gmail.com.
}

Article DOI: https://doi.org/10.37284/eajes.3.1.348

\section{Date Published: ABSTRACT}

23 June 2021 The purpose of this study was to assess the influence of sibling relationships on the development of maladjusted behaviour among pupils in public primary

Keywords: schools in Yatta Sub-County, Machakos County, Kenya. The study was guided by the Ecological Systems Theory. A mixed methodology was applied and the

Sibling Relationships,

Maladjusted, concurrent triangulation design in which the researcher implemented the quantitative and qualitative methods during the same timeframe and with equal

Behaviour Patterns. weight. The target population consisted of 64 headteachers, 128 teachercounsellors, 512 parents' representatives and 4352 pupils in classes VI \& VII all totalling 5056. Using the Central Limit Theorem, 12 public primary schools $(18.8 \%)$ of 64 and 200 respondents were sampled. Stratified sampling was used to create four strata based on the number of zones in the Yatta Sub-County. From each zone, three headteachers, three parents' representatives, 18 teachercounsellors and 26 pupils in classes VI \& VII were selected using simple random sampling to eliminate bias. This procedure enabled the researcher to sample 12 headteachers and 72 teacher-counsellors. Data analysis began by identifying common themes. Qualitative data were analysed thematically along with the objectives and presented in narrative forms. Quantitative data were analysed descriptively using frequencies and percentages and inferentially using Pearson's Product Moment Correlation Analysis with the help of Statistical Packages for Social Science (SPSS Version 23) and presented using tables. The study established that cases of maladjusted behaviours among pupils are on the rise with sibling relationships and interactions being the main determinant. In other words, activities that siblings engage in such as modelling juniors, playing together, engaging in social interaction activities and punishing juniors contribute to the development of maladjusted behaviours among pupils. Thus, the study recommends that parents should design age-appropriate tasks for older siblings to undertake which may enable them to act as role models for their juniors.

147 | This work is licensed under a Creative Commons Attribution 4.0 International License. 


\section{APA CITATION}

Kavwei, B., \& Cheseto, N. (2021). Influence of Sibling Relationships on Development of Maladjusted Behaviour among Pupils in Public Primary Schools in Yatta Sub-County, Machakos County, Kenya. East African Journal of Education Studies, 3(1), 147-157. https://doi.org/10.37284/eajes.3.1.348.

\section{CHICAGO CITATION}

Kavwei, Betty, and Nancy Cheseto. 2021. "Influence of Sibling Relationships on Development of Maladjusted Behaviour among Pupils in Public Primary Schools in Yatta Sub-County, Machakos County, Kenya”. East African Journal of Education Studies 3 (1), 147-157. https://doi.org/10.37284/eajes.3.1. 348.

\section{HARVARD CITATION}

Kavwei, B. and Cheseto, N. (2021) "Influence of Sibling Relationships on Development of Maladjusted Behaviour among Pupils in Public Primary Schools in Yatta Sub-County, Machakos County, Kenya", East African Journal of Education Studies, 3(1), pp. 147-157. doi: 10.37284/eajes.3.1. 348.

\section{IEEE CITATION}

B. Kavwei, and N. Cheseto, "Influence of Sibling Relationships on Development of Maladjusted Behaviour among Pupils in Public Primary Schools in Yatta Sub-County, Machakos County, Kenya”, EAJES, vol. 3, no. 1, pp. 147-157, Jun. 2021.

\section{MLA CITATION}

Kavwei, Betty, and Nancy Cheseto. "Influence of Sibling Relationships on Development of Maladjusted Behaviour among Pupils in Public Primary Schools in Yatta Sub-County, Machakos County, Kenya". East African Journal of Education Studies, Vol. 3, no. 1, Jun. 2021, pp. 147-157, doi:10.37284/eajes.3.1.348.

\section{INTRODUCTION}

The home environment plays an important role in shaping the behaviour of children. Bradley, Crowyn, Burchinal, McAdoo and Coll (2001) posit that the family serves as the primary initial context within which children learn appropriate and inappropriate interaction patterns, especially with their siblings. Siblings represent a family dimension the influences the development of maladjusted behaviour patterns among primary school pupils. Having older siblings may be advantageous for the children's development of healthy behaviour patterns. Cognizant of these assertions, Updegraff, McHale, Killoren and Rodriguez (2010) conducted a study in the Netherlands which revealed that siblings are a fixture in the family lives of children and adolescents, and a body of work documents their role in one another's everyday experiences as companions, confidants, combatants, and as the focus of social comparisons. According to Updegraff et al. (2010), sibling relationships and their experiences contribute towards youth development of desirable or undesirable behaviour patterns.

Siblings' position in the family gives rise to social psychological processes, with lifelong implications for individual child's development and adjustment (Updegraff et al., 2010). These findings point to the fact that sibling roles may acquire crucial importance on the development of healthy or maladjusted behaviour patterns since siblings share many thousands of hours of social and emotional interaction with each other in the same context. However, cases of development of maladjusted behaviour have become a common phenomenon which brings into question the extent to which home environment contributes towards such behaviour. In Australia, Wachs (1993) asserts that many pupils in primary schools are involved in various antisocial behaviours such as stealing, fighting, vandalism and all manner of violence. Wachs (1993) further asserts that deviant behaviour such as violence, substance abuse, and the development of clinical disorders is often associated with peer influence and society.

In Australia, Fagan and Najman (2001) note that play is common for siblings and is a powerful setting for child interactions where they can talk, learn, teach, socialise, and apply what they know. In addition, young children observe and try to imitate their older siblings, and older siblings teach them physical, social, cultural, and academic skills (Fagan \& Najman, 2001). This implies that siblings' greater shared experience, siblings may be more aware of each other and be more effective teachers, that is, older siblings and learners, that is, younger siblings. In other words, when siblings interact, younger siblings, in particular, may benefit as their ways of behaviour change.

In Germany, Steelman, Powell, Werum and Carter (2002) anticipated tenets of social learning theory in

148 | This work is licensed under a Creative Commons Attribution 4.0 International License. 
demonstrating that higher status, older siblings tended to be more influential models and that model similarity, that is, same-gender siblings, enhanced a model's behavioural impact. An important insight from this work was that sibling gender constellation effects emerged not only via parent-driven dynamics such as gendered differential treatment but also from siblings' direct experiences with one another (Steelman et al., 2002). This points to the fact that children benefit from siblings in that they allow for early socialisation that can begin to prepare them for more successful peer interactions. That is, siblings contribute to children's development of social skills and their understanding of relationships because they are together all the time.

In many countries in Sub-Saharan Africa, Stoneman, Brody, Churchill and Winn (1999) assert that siblings have direct influences on the development of healthy relationships and behaviour patterns among their colleagues such as when they shape behaviour during everyday interactions to serve as sources of social support or act as role models. However, Stoneman et al. (1999) note that less attention has been paid to the ways siblings influence one another indirectly in their roles as building blocks of the family structure and through ripple effects of their behaviour and experiences throughout the family system. For example, a study conducted in Nigeria by Omogbemi and Ebuehi (2011) established that siblings' extensive contact and companionship during childhood and adolescence, increasingly outside the direct supervision of parents or other adults, provides ample opportunity for them to shape one another's behaviour and socioemotional development and adjustment. Omogbemi and Ebuehi (2011) revealed that direct sibling influences are grounded in developmental or social learning models, suggesting that, by virtue of their everyday involvement, siblings can promote positive development as well as adjustment problems. it is further noted that, through their conflicts, for example, siblings can develop skills in perspective taking, emotion understanding, negotiation, persuasion, and problem-solving.

Besides, these competencies extend beyond sibling relationships and are linked to later social competence, emotional understanding and peer relationships. In adolescence, siblings also contribute to positive developmental outcomes, including prosocial behaviour. However, in KwaZulu Natal Province in South Africa, Zitha (2012) notes that not all of what siblings learn in their exchanges are positive and an increasing focus in the past two decades has been on sibling influences on adolescents' risky behaviour and adjustment problems.

Zitha (2012) further asserts that sibling conflicts in childhood, for example, are associated with concurrent and later deviance, school problems, bullying, substance use and internalising symptoms. While keeping with these assertions, Manh (2013) carried out a study in Lesotho which established that siblings' coercive interaction styles learned in the context of sibling conflict extend to aggression with peers and antisocial behaviours. Manh (2013) indicated that, besides providing a setting for practising coercive behaviours, reinforcing antisocial behaviours such as deviant talk, and colluding to undermine parental authority, siblings (especially older ones) provide each other with models of deviant behaviour and serve as gatekeepers to delinquent peers and risky activities. Manh (2013) further notes that siblings may expose each other to settings and peer groups in which substance use is accepted.

A meta-analysis of twin and adoption studies by Rhee and Waldman (2002) posits that older sibling may transmit beliefs about sexual activity and childbearing; provide information regarding sexual activities, including safe sexual practices; and even exert pressure on younger ones to engage in sexual activities. According to Rhee and Waldman (2002), older siblings may play a matchmaker role, introducing their brothers and sisters to partners who are older and possibly more experienced sexually, leading to an increased risk for early sexual activity. In Kenya, the scenario is the same with cases of pupils' indiscipline being on the rise in most public primary schools. Gitome, Katola and Nyabwari (2013) report that a great deal of emphasis in primary schools is placed on helping children regulate their behaviour in order to succeed in social interactions. In Kenya, siblings play an important role in shaping the behaviour patterns of their brothers and sisters (Mvungu, 2010). 
A study conducted in Nakuru Municipality by Muola, Ngung'u and Ngesa (2009) established that older siblings serve as "agents of socialisation" who teach younger siblings by example about informal social behaviours such as how to act around friends. Muola et al. (2009) noted that younger siblings are also highly susceptible to acquiring older siblings' maladjusted habits including underage drinking and smoking. According to Muola et al. (2009), younger siblings with diverse interests or more dominant personalities can affect older siblings similarly and thus parents must be able to distinguish between healthy sibling relationships and damaging abuse. Muola et al.'s findings further assert that sibling rivalry is a normal and mostly harmless part of growing up. Siblings often compete without anyone getting hurt. These sometimes fierce but balanced comparisons regarding achievement, attractiveness and social relations with peers may actually strengthen sibling ties.

For example, fair and balanced competition teaches children how to share, compromise, win without humiliation and lose without self-debasement. These findings point to the fact that individual differences among siblings impact their relationships. In other words, when children are younger, temperament is important in sibling relationships, but for older children, relationships are influenced by their personality and social and cognitive skills. In Yatta Sub-county, Mutie (2015) underscore the fact that children's personalities, social and cognitive skills, self-concepts, values, and sense of protection from the outside world are influenced by their sibling relationships. Mutie (2015) asserts that siblings also affect children's roles in peer groups, in selecting friends, and in the larger world. The interests and skills children develop in their sibling relationships are often repeated later in choosing an occupation, mate or deciding on the number of children to have. However, Mutie (2015) as did other empirical researchers have not articulated the extent to which different forms of sibling relationships and activities undertaken during interactions influence the development of maladjusted behaviour among primary school pupils.

\section{Statement of the Problem}

Siblings play an important role in shaping the behaviour patterns of pupils in primary schools based on their regular interactions and activities in which they engage in. However, in Yatta Subcounty, the situation is different since cases of maladjusted behaviour problems such as inattentiveness, bullying, violence, drug abuse, hitting other pupils, teasing other pupils, yelling and complaining in primary schools are on the rise. Instances of delinquents are on the rise in most primary schools occasioned by maladjusted behaviour patterns. As stated in the background, Mutie (2015) notes that many incidences of tearfulness, engaging in self-destructive behaviours, withdrawing from friends and previously-enjoyed activities, increasing amounts of time spent alone, increased absences from school, using drugs or alcohol to help combat the feelings of sadness and stress, depression, fighting and acting out has become a common phenomenon among pupils in primary schools in Yatta Sub-county. Despite these assertions, few empirical studies have interrogated the extent to which sibling relationships within the home environment influence development of maladjusted behaviours among pupils in public primary schools.

\section{Objective of the Study}

The study sought to assess the influence of sibling relationships on the development of maladjusted behaviour among pupils in public primary schools in Yatta Sub-county, Machakos County, Kenya.

\section{THEORETICAL FRAMEWORK}

This study was guided by the ecological systems theory which was proposed by Bronfenbrenner (1986). Like socio-cultural perspectives, ecological approaches recognise immediate experiences of pupils who manifest maladjusted behaviour in context but also capture patterns of interaction between individuals, groups and institutions as they unfold over time. In his research, Bronfenbrenner (1986) perceived four aspects of the ecology in which pupils who manifest maladjusted behaviour grow up, that is, microsystems, mesosystems, exosystems, and macrosystems. Microsystems relate to pupils who manifest maladjusted behaviour 
experiences and interactions with peers, teachers and caregivers in everyday settings, at home and child care centres, among other places. Mesosystems are the relation between these different microsystems such as the complementary and conflicting practices and belief systems at home and the informal or formal communications between parents and teachers. Exosystems are areas of social life in which pupils who manifest maladjusted behaviour do not themselves participate but which nonetheless impact their lives and well-being through interconnections with microsystems.

Another feature of ecological theory concerns the role of pupils who manifest maladjusted behaviour in their development. In this view, pupils who manifest maladjusted behaviour develop through everyday interactions with their caregivers and with other pupils who manifest maladjusted behaviour, symbols and objects in a given context. According to Bronfenbrenner (1986), activities and forms of interactions that siblings engage in at home play a significant role in the development of maladjusted behaviour among primary school pupils. Thus, the rationale of using the ecological theory in this study is that it recognises the fact that the home microsystems are composed of parents, siblings and media content with different characteristics which contribute to behaviour development among schoolgoing children.

\section{RESEARCH METHODOLOGY}

The study adopted a mixed methodology and concurrent triangulation design in which the researcher implemented the quantitative and qualitative methods during the same timeframe and with equal weight. The target population consisted of 64 headteachers, 128 teacher-counsellors, 512 parents' representatives and 4,352 pupils in classes VI \& VII, all totalling 5,056. Using the Central Limit Theorem, 12 public primary schools (18.8\%) of 64 and 200 respondents were sampled. Stratified sampling was used to create four strata based on the number of zones in the Yatta Sub-county. From each zone, three headteachers, three parents' representatives, 18 teacher-counsellors and 26 pupils in classes VI \& VII were selected using simple random sampling to eliminate bias. This procedure enabled the researcher to sample 12 headteachers and 72 teacher-counsellors. Questionnaires were used to collect data from teacher-counsellors, interview schedules for headteachers and parents' representatives, whereas an observation checklist was used to gather data from pupils. Qualitative data were analysed thematically along with the objectives and presented in narrative forms. Quantitative data were analysed descriptively using frequencies and percentages and inferentially using Pearson's Product Moment Correlation Analysis with the help of Statistical Packages for Social Science (SPSS Version 23) and presented using tables.

\section{RESULTS AND DISCUSSIONS}

In this study, 72 questionnaires were administered to teacher-counsellors and, in return, 38 questionnaires were filled and returned. The researcher also interviewed 11 headteachers, 10 parents' representatives and conducted observation schedules among 90 pupils in classes VI \& VII. This accounted for a cumulative response rate of $89.5 \%$ (179 participants) which is consistent with the assertions of Creswell (2014) that a response rate above $75.0 \%$ is adequate and of suitable levels to allow for generalisation of the outcomes to the target population.

Status of Maladjusted Behaviour among Pupils in Public Primary Schools

The study sought to assess the levels of manifestation of maladjusted behaviour patterns among pupils in public primary schools. The findings are presented in Table 1; 
Table 1: Views of Teacher-counsellors on Manifestation of Maladjusted Behaviour among Pupils in Public Primary Schools

\begin{tabular}{lclllll}
\hline Forms of Maladjusted Behaviour & Very Often & \multicolumn{7}{l}{ Rarely Never } \\
\hline & $\mathrm{f}$ & $\%$ & $\mathrm{f}$ & $\%$ & $\mathrm{f}$ & $\%$ \\
Bullying others & 37 & 54.4 & 24 & 35.3 & 7 & 10.3 \\
Hitting others & 40 & 58.8 & 22 & 32.4 & 6 & 8.8 \\
Violence and fighting & 21 & 30.9 & 30 & 44.1 & 17 & 25.0 \\
Drug abuse & 27 & 39.7 & 32 & 47.1 & 9 & 13.2 \\
Absenteeism & 41 & 60.3 & 20 & 29.4 & 7 & 10.3 \\
Withdrawal from friends & 34 & 50.0 & 27 & 39.7 & 7 & 10.3 \\
Depression & 36 & 52.9 & 28 & 41.2 & 4 & 5.9 \\
Engaging in self-destructive behaviours & 32 & 47.1 & 25 & 36.8 & 11 & 16.1 \\
\hline
\end{tabular}

Table 1 shows that slightly more than half, $37(54.4 \%)$ of the teacher-counsellors indicated that pupils very often bully others, 24(35.3\%) indicated they rarely do, whereas $7(10.3 \%)$ stated that pupils never bully others. Slightly more than half, $40(58.8 \%)$ of the teacher-counsellors indicated that pupils very often hit others, $22(32.4 \%)$ indicated they rarely do, whereas $6(8.8 \%)$ indicated that pupils never hit others. On the question of violence and fighting, 21(30.9\%) of the teacher-counsellors stated that pupils very often engage in violence and fight their peers, 30(44.1\%) stated that they rarely do, while a quarter, 17(25.0\%) stated that pupils never fight each other nor do they engage in violence. Slightly more than a third, 27(39.7\%) of the teacher-counsellors stated that primary school pupils very often abuse drugs, 32(47.1\%) stated that pupils rarely abuse drugs, whereas $9(13.2 \%)$ said they never abuse drugs. On absenteeism, the majority, 41(60.3\%) of the teacher-counsellors, stated that pupils very often absent themselves from school, 20(29.4\%) said that they rarely do whereas $7(10.3 \%)$ said they never do. Half, 34(50.0\%) of the teacher-counsellors noted that pupils very often withdraw from friends, 27(39.7\%) stated they rarely do, while $7(10.3 \%)$ said they never do. Slightly more than half, $36(52.9 \%)$ of the teachercounsellors stated that very often pupils have been victims of depression, $28(41.2 \%)$ said they have rarely been victims of depression, whereas $4(5.9 \%)$ said that they never have. A fair proportion, $32(47.1 \%)$ of the teacher-counsellors noted that very often pupils have engaged in self-destructive behaviours, $25(36.8 \%)$ stated that they rarely do, while $11(16.1 \%)$ noted that pupils have never engaged in self-destructive behaviours.
These findings corroborate the findings of an integrative review by Koole (2009) who also established that maladjusted behaviour patterns have become a common phenomenon among learners. According to Koole (2009), such maladjusted behaviours include; tearfulness, engaging in self-destructive behaviours, withdrawing from friends and previously-enjoyed activities, increasing amounts of time spent alone, increased absences from school, using drugs or alcohol to help combat the feelings of sadness and stress, fighting and acting out. Koole (2009) further notes that maladjusted children continue to misbehave in spite of the threat of punishment. These findings also lend credence to the assertions of Tucker et al. (1999) that, in India, maladjusted behaviour means excessive aggression or destructiveness which also include unnatural fears, excessive inhibition, and academic underachievement. These findings are indicative of the fact that cases of maladjusted behaviour patterns are on the rise among learners in primary schools with deleterious effects on their behaviour patterns.

During the interviews, headteachers and parents' representatives also responded in favour of the view that cases of bullying, violence, fighting and abuse of drugs have become common among learners. Headteacher, H1, observed:

In my school, we have had frequent cases of bullying, pupils fighting and harm their peers. On some occasions, we have had to send pupils home due to cases of drug abuse.

Parents' representatives supported these views and further stated that, on many occasions, schools have 
had to call frequent committee meetings to discuss cases of pupils who have been involved in fighting, suspend those who bully others and engage in drug abuse. Parents' representative, PR1, noted:

In my primary school, a week may not end before we receive a call from the school head to attend a meeting where a learner has to be suspended for fighting or hitting peers or have been caught with drugs.

From the records in the department of counselling, the researcher also observed that cases of violence and drug abuse among learners are many. The researcher also noted that, from the minutes of weekly meetings, key issues being deliberated upon revolved around cases of violence and drug abuse among learners. The scenario is the same when it comes to cases of absenteeism, cases of depression and engagement in self-destructive behaviours among pupils. This implies that many pupils exhibit cases of lack of empathy, lack of remorse, false sense of grandiosity, persistent negativity, chronic annoyance and irritability and low self-esteem.

Sibling Relationships and Development of Maladjusted Behaviour among Primary School Pupils

The study sought to assess the influence of sibling relationships on the development of maladjusted behaviour among primary school pupils. Results are shown in Table 2;

Table 1: Teacher-counsellors' Views on the Influence of Sibling Relationships on the Development of Maladjusted Behaviour among Primary School Pupils

\begin{tabular}{llllll}
\hline Test Statements & SA & A & U & D & SD \\
\cline { 2 - 6 } & \% & \% & \% & \% & \% \\
\hline $\begin{array}{l}\text { Sibling activities such as modelling of juniors influence } \\
\text { the extent to which their children develop maladjusted } \\
\text { behaviours }\end{array}$ & 80.5 & 8.5 & 1.5 & 5.5 & 4.0 \\
\hline $\begin{array}{l}\text { Siblings play together determine pupils' development of } \\
\text { maladjusted behaviours }\end{array}$ & & & & & \\
\hline $\begin{array}{l}\text { Sibling engage and interact with each other which has } \\
\text { influenced development of maladjusted behaviours }\end{array}$ & 69.5 & 14.5 & 2.5 & 3.0 & 1.5 \\
\hline $\begin{array}{l}\text { The ability of siblings to punish their juniors play an } \\
\text { important role in determining the extent to which their } \\
\text { children develop maladjusted behaviours }\end{array}$ & & & & & \\
\hline
\end{tabular}

Table 2 reveals that $55(80.5 \%)$ of the teachercounsellors strongly agreed with the view that sibling activities such as modelling of juniors influence the extent to which their children develop maladjusted behaviours, as did 6(8.5\%) who agreed. However, only a paltry $1(1.5 \%)$ were undecided, $4(5.5 \%)$ disagreed, whereas $3(4.0 \%)$ strongly disagreed. The study also found out that 53(78.5\%) of the teacher-counsellors strongly agreed with the view that siblings play together to determine pupils' development of maladjusted behaviours, while $10(14.5 \%)$ agreed. However, 2(2.5\%) were undecided, 2(3.0\%) disagreed whereas 1(1.5\%) strongly disagreed. These findings are consistent with the findings of a study carried out in the Netherlands in which Updegraff et al. (2010) found that siblings are a fixture in the family lives of children and adolescents, and a body of work documents their role in one another's everyday experiences as companions, confidantes, combatants, and as the focus of social comparisons. According to Updegraff et al. (2010), sibling relationships and their experiences contribute towards youth development of desirable or undesirable behaviour patterns. This implies that sibling roles may acquire crucial importance on the development of healthy or maladjusted behaviour patterns since siblings share many thousands of

153 | This work is licensed under a Creative Commons Attribution 4.0 International License. 
hours of social and emotional interaction with each other in the same context.

The study also revealed that $47(69.5 \%)$ of the teacher-counsellors strongly agreed with the view that sibling engages in interact with each other which has influenced the development of maladjusted behaviours, whereas $8(12.0 \%)$ agreed. However, 2(2.0\%) were undecided, 7(10.0\%) disagreed whereas $5(6.5 \%)$ strongly disagreed. These findings lend credence to the assertions of Fagan and Najman (2003) that play is common for siblings and is a powerful setting for child interactions where they can talk, learn, teach, socialise, and apply what they know. In addition, young children observe and try to imitate their older siblings, and older siblings teach them physical, social, cultural, and academic skills (Fagan \& Najman, 2003). This implies that through greater shared experience, siblings may be more aware of each other and be more effective teachers, that is, older siblings and learners, that is, younger siblings. In other words, when siblings interact, younger siblings, in particular, may benefit as their ways of behaviour change.

The study also revealed that 51(74.5\%) of the teacher-counsellors strongly agreed with the view that the ability of siblings to punish their juniors play an important role in determining the extent to which their children develop maladjusted behaviours, whereas 12(17.0\%) agreed. At the same time, $2(2.5 \%)$ were undecided, 3(3.5\%) disagreed, whereas $2(2.5 \%)$ strongly disagreed.

These findings corroborate the assertions of Stoneman et al. (1999) that siblings have direct influences on the development of healthy relationships and behaviour patterns among their colleagues such as when they shape behaviour during everyday interactions to serve as sources of social support or act as role models. These findings are indicative of the fact that role of siblings in shaping the behaviour patterns of their brothers and sisters cannot be overlooked since what siblings learn have influences on their juniors' risky behaviour and adjustment problems.

To verify the influence of sibling relationships on the development of maladjusted behaviour among pupils in public primary schools, data were collected on how often siblings are involved in behaviour modification of the juniors (Very Often $=$ 5 , Often $=4$, Sometimes $=3$, Rarely $=2 ;$ Never $=1$ ) and the number of pupils with cases of maladjusted behaviour patterns in public primary schools. The results are shown in Table 3:

Table 2: Frequency of Siblings' Involvement in Behaviour Modification of Juniors and the Number of Pupils with Cases of Maladjusted Behaviour in Primary Schools

\begin{tabular}{lc}
\hline $\begin{array}{c}\text { Frequency of Siblings' Involvement in Behaviour } \\
\text { Modification of their Juniors }\end{array}$ & $\begin{array}{c}\text { Number of Pupils with Cases } \\
\text { of Maladjusted Behaviour }\end{array}$ \\
\hline 5 & 67 \\
5 & 89 \\
4 & 103 \\
4 & 127 \\
3 & 145 \\
3 & 151 \\
2 & 168 \\
1 & 177 \\
1 & 198 \\
1 & 201 \\
1 & 211 \\
\hline
\end{tabular}

Table 3 shows that parents who very often involve siblings in shaping and modifying the behaviour patterns of their juniors have seen a reduction in the number of cases of maladjusted behaviour patterns among pupils in public primary schools. This indicates that the role of siblings and their activities 
or interactions play a major part in behaviour modification of children and, when positive, such interactions lead to reduced cases of maladjusted behaviour patterns among pupils. These results were subjected to Pearson's Product Moment Correlation Analysis and the results are shown in Table 4:

Table 3: Frequency of Siblings' Involvement in Behaviour Modification of Juniors and Development of Maladjusted Behaviour among Pupils in Primary Schools

\begin{tabular}{llll}
\hline & & $\begin{array}{l}\text { Sibling } \\
\text { Relationships }\end{array}$ & $\begin{array}{l}\text { No. of Pupils with Cases } \\
\text { of Maladjusted } \\
\text { Behaviour }\end{array}$ \\
\hline Sibling Relationships & $\begin{array}{l}\text { Pearson Correlation } \\
\text { Sig. (2-tailed) }\end{array}$ & 1 & $-.970^{*}$ \\
& N & 5 & .000 \\
No. of Pupils with & Pearson Correlation & $-.970^{*}$ & 11 \\
Cases of Maladjusted & Sig. (2-tailed) & .000 & 1 \\
Behaviour & N & 11 & 11 \\
\hline
\end{tabular}

*. Correlation is significant at the 0.05 level (2-tailed).

Table 4 shows that there is a strong positive correlation between sibling relationships and the number of pupils with maladjusted behaviour in public primary schools $r(11)=-0.970, p=0.000$ at $\alpha=0.05)$. These findings further affirm the fact that sibling relationships are important in shaping the behaviour patterns of pupils in primary schools. This implies that siblings are more aware of each other and be more effective teachers, that is, older siblings and learners, that is, younger siblings.

Thematic Analysis of the Influence of Sibling Relationships on the Development of Maladjusted Behaviour among Primary School Pupils

The researcher also conducted interviews among headteachers and parents' representatives on the influence of sibling relationships on the development of maladjusted behaviour among pupils in primary schools. The interviewees also supported the views of teacher-counsellors that activities which are undertaken by siblings in different homes such as modelling of juniors influence the extent to which their juniors develop maladjusted behaviours. Parents' representative, PR2, observed,

In my home, my older children take care of their younger brothers and sisters whenever I am not around. This interaction has enabled my younger to learn from the older siblings. In other words, sibling interactions are key because they shape the behaviour of their juniors.

These views were supported by the headteachers who also observed that, due to demanding economic situations where parents spend much of their time undertaking different duties. Headteacher, H2, noted;

On many occasions, parents leave their younger children with their older siblings who take the roles of disciplinarians. Sometimes, the older siblings come for their juniors at school owing to the commitment of their parents. This makes the children emulate the behaviour patterns of their siblings.

From these verbatims, it is evident that behavioural and play activities practised by siblings tend to shape the behaviours of their younger brothers and sisters. Just like quantitative findings, these qualitative findings affirm that sibling roles may acquire crucial importance on the development of healthy or maladjusted behaviour patterns since siblings share many thousands of hours of social and emotional interaction with each other in the same context. When siblings interact, younger siblings, in particular, may benefit as their ways of behaviour change. The interviewees further responded in favour of the view that the ability of siblings to punish their juniors play an important role in determining the extent to which their brothers and

155 | This work is licensed under a Creative Commons Attribution 4.0 International License. 
sisters develop maladjusted behaviours. Headteachers, H3, noted;

In homes where older children reprimand their juniors for having done something wrong, children learn desirable behaviour patterns and thus, tend not to develop maladjusted behaviours

This affirms that role of siblings in shaping the behaviour patterns of their brothers and sisters cannot be overlooked since what siblings learn have influences on their juniors' risky behaviour and adjustment problems.

\section{SUMMARY AND CONCLUSIONS}

The study has established that many primary school pupils exhibit incidences of maladjusted behaviour patterns. There are many cases of bullying, violence, fighting and abuse of drugs that have become rampant among pupils in public primary schools with many of such pupils exhibiting instances of lack of empathy, lack of remorse, false sense of grandiosity, persistent negativity, chronic annoyance and irritability and above all, low selfesteem. From the study findings, sibling relationships, interactions and activities have also been found to be key shapers of children's behaviour. Forms of interactions and activities which are undertaken by siblings in different homes such as modelling, advising and punishing juniors influence the extent to which their juniors develop maladjusted behaviours.

\section{Recommendations}

As a practice, the study recommends that parents should design age-appropriate tasks for older siblings to undertake which may enable them to act as role models for their juniors. On policy, the study recommends that the government should organise seminars, workshops and conferences to educate parents on their role in behaviour modification despite their level of education, socio-economic status and thus, change their attitude towards the value of their children's education as a way of reducing cases of maladjusted behaviour patterns among primary school-going children.

\section{REFERENCES}

Bradley, R., Crowyn, R., Burchinal, M., McAdoo, H. \& Coll, C. (2001). The home environments of children in the United States, Part II: Relations with behavioural development through age thirteen. Child Development, 72, 1868-1886.

Bronfenbrenner, U. (1986). Ecology of the family as a context of human development: Research perspectives. Developmental Psychology 22(6): 723-742.

Creswell, J. (2014). Research design: qualitative, quantitative and mixed methods. Thousand Oaks, California: Sage Publications.

Ebuehi, O. M., \& Omogbemi, K. B. (2011). Juvenile delinquency among students of an approved sheltered girls' school in Lagos, Nigeria. Nigerian quarterly journal of hospital medicine, 21(1), 50-58.

Fagan, A. \& Najman, J. (2003). Sibling influences on adolescent delinquent behaviour: An Australian longitudinal study. Journal of Adolescence. 5(26):546-558.

Gitome, J., Katola, M. \& Nyabwari, B. (2013). Correlation between pupils' discipline and performance in the Kenya Certificate of Primary Education. International Journal of Education and Research, 1(8): 1-10.

Koole, S. (2009). The psychology of emotion regulation: An integrative review. Cognition \& emotion, 23, 4-41.

Manh, N. (2013). Role of families in educating spoiled children in Lesotho. Vietnam National University, Hanoi.

Muola, J. M., Ndung'u, N. M., \& Ngesa, F. (2009). The relationship between family functions and juvenile delinquency: A Case of Nakuru Municipality, Kenya. African Research Review, 3(5).

Mutie, J. (2015). Effects of emotionally absent parents on the behaviour of adolescents in selected secondary schools in Machakos County, Kenya. Unpublished Thesis, Kenyatta University. 
Mvungu, E. (2010). An investigation into the effectiveness of rehabilitation programmes in selected centres of former street children and adolescents in Nairobi Kenya. Unpublished master's thesis. Kenyatta University, Kenya.

Omogbemi, K. \& Ebuehi, O. (2011). Juvenile delinquency among students of an approved sheltered girls' school in Lagos, Nigeria.

Rhee, S. H., \& Waldman, I. D. (2002). Genetic and environmental influences on antisocial behavior: a meta-analysis of twin and adoption studies. Psychological Bulletin, 128(3), 490.

Steelman, L. C., Powell, B., Werum, R., \& Carter, S. (2002). Reconsidering the effects of sibling configuration: Recent advances and challenges. Annual review of sociology, 28(1), 243-269.

Stoneman, Z., Brody, G. H., Churchill, S. L., \& Winn, L. L. (1999). Effects of residential instability on Head Start children and their relationships with older siblings: Influences of child emotionality and conflict between family caregivers. Child Development, 70(5), 12461262.

Tucker, C. J., Updegraff, K. A., McHale, S. M., \& Crouter, A. C. (1999). Older siblings as socialisers of younger siblings' empathy. The Journal of Early Adolescence, 19(2), 176-198.

Updegraff, K., McHale, S., Killoren, S. \& Rodriguez, S. (2010). Cultural variations in sibling relationships. New York: Springer.

Wachs, T. D. (1993). Nature of relations between the physical and social microenvironment of the two-year-old child. Early development and parenting, 2(2), 81-87.

Zitha, M. (2012). Role of Families in Social and Economic Empowerment of Individuals. Human Sciences Research Council of South Africa. 